\title{
Nilai-Nilai Kearifan Lokal Dari Naskah Wawacan Carios Munada
}

\author{
Dewi Ratih
}

Program Studi Pendidikan Sejarah, FKIP, Universitas Galuh Ciamis

\begin{abstract}
Abstrak
Naskah wawacan carios munada ditulis sekitar abad ke-19. Naskah tersebut menuturkan peristiwa yang terjadi di Bandung pada tahun 1845 menggunakan Bahasa Sunda. Beberapa nilai-nilai kearifan lokal di dalam naskah wawacan carios munada ini dapat dianalisis menggunakan teori dan pendekatan hermeneutika dan interpretasi yang dikembangkan dari Palmer, artinya pendekatan hermeneutika yang digunakan adalah metodologi filologi umum, bukan metodologi penafsiran kitab suci. Dengan menggunakan pendekatan hermeneutika nilai-nilai kearifan lokal yang tertulis di dalam naskah akhirnya dapat dikaji secara konperhensif. Karangan di dalam naskah ini menggunakan bentuk puisi atau disebut dangding dan ditulis oleh W.P.Tj. M. Kartadinata dari Banoncinawi Priangan. Sampai saat ini belum dapat diidentifikasi dimana sebenarnya lokasi Banoncinawi itu berada. Salah satu nilai kearifan lokal yang berada di dalam naskah wawacan carios munada tersebut adalah bentuk bahasa Sunda yang sudah menggunakan undak usuk basa.
\end{abstract}

\section{Kata Kunci: Wawacan Carios Munada, Puisi, Danding}

\section{Pendahuluan}

Naskah Wawacan Carios Munada ini sekarang tersimpan di Perpustakaan Universitas Leiden. Naskahnya diberi kode nomer Mal. 1612 dan Cod. Dr. 6482. Naskah ini ditulis pada kertas folio (34 x $22 \mathrm{~cm})$. Ada tiga macam kertas yang digunakan untuk menuliskan naskah ini. 1. Kertas bergaris membayang, 2. Kertas tidak bergaris yang halus (licin), dan 3. Kertas gambar tebal. Pada bagian kertas bergaris membayang terdapat tulisan berbunyi G, Kolff \& Co. Batavia.

Tampak juga ada garis dengan pensil yang dijadikan. Naskah ini dijilid dengan karton cukup tebal yang dibungkus dengan kertas berwarna biru. Pada jilid depan bagian dalam terdapat tulisan atau cap yang berbunyi Taslim Soekbinderij Salemba G. Paseban, kiranya menunjukan perusahan yang menjilid naskah itu. Kondisi kertasnya masih baik dan keseluruhan naskahnya masih utuh. Tinta untuk menuliskan naskah ini adalah tinta berwarna hitam, Hurufnya berupa tulisan yang tertulis rapi sehingga mudah dibaca. Pada jilid naskah depan bagian luar tertera judul naskah yang berbunyi (219 Wawatjan Tjarios Moenada anoe parantos kadjadian hoeroe-hara di negri Bandoeng di kaping 30 Boelan Desember 1842).

Angka 219 kiranya menunjukan nomor naskah yang dibuat oleh mungkin redaktur atau tata usaha Balai Pustaka di Jakarta. Rupanya naskah ini, bersama sejumlah naskah lainnya, pada mulanya dikirimkan ke Leiden. Alasan penolakan, tampaknya karena isi karangannya mengungkapkan kekurangan patutan prilaku dan kelemahan pejabat pemerintah kolonial yang adalah orang Eropa. Naskah ini diperuntukkan bagi Balai Pustaka, badan 
penerbitan yang diselenggarakan oleh pemerintah, terlihat juga dari pernyataan pengarang yang sesuai dengan kebijakan pemerintah kolonial pada waktu itu dalam bidang penerbitan buku, yaitu menciptakan keadaan masyarakat dan negara yang tertib dan aman. Dikemukakan, selain pengarang mengakui kekuasaan pemerintah kolonial yang dipegang oleh Maharatu Wilhelmina di Nederlan dan Raja Hindia Kanjeng Tuan Besar Gubernur Jenderal, juga menyanjungnya dengan menyatakan bahwa Maharatu Nederlan itu bijaksana dan raja Hindia itu adil, berbudi, dan sayang terhadap rakyat.

Di samping pengarang mengajukan bukti kemurahan pemerintah terhadap rakyatnya berupa sekolah-sekolah yang didirikan di setiap distrik (kewedanan), onderdistrik (kecamatan), dan bahkan setiap Desa yang membawa masyarakat pintar dan kreatif, serta memberi petuah kepada pembaca (masyarakat pribumi). Supaya segala kemurahan pemerintah diterima dengan penuh kesadaran dengan cara giat bekerja dan mengabdi dan setia kepada pemerintah secara sungguh.

Pada halaman 1 teks naskah tertera tambahan judul Beresna oeroesan dina tahoen 1845. Dikarang sareng di dangding koe W.P.Tj. M. Kartadinata di Banontjinawi Preangan. Dari keterangan mengenai judul naskah tersebut, dapat diketahui bahwa judul karangan yang terdapat pada naskah itu yang kemudian dipakai judul dalam penerbitan naskah ini yang kemudian dipakai judul dalam penerbitan naskah ini adakah Wawacan Carios Munada. Disamping itu, dapat diketahui pula bahwa karangan itu menuturkan peristiwa huruhara yang terjadi di Bandung 30 Desember 1845. Karangan disusun dalam bentuk puisi oleh Mas Kartadinata di Banoncinawi, Priangan. Sampai sekarang belum dapat diidentifikasi lokasi Banoncinawi berada.

\section{Tinjauan Pustaka}

\section{A. Teori Hermeneutika dan Interpretasi}

Sejarah definisi hermeneutika ini masih terus berkembang. Richard E. Palmer mendefinisikan hermeneutika menjadi enam. 1). Hermeneutika sebagai teori penafsiran kitab suci (theory of biblical exegesis), 2). Hermeneutika sebagai metodologi filologi umum (general philological methodology), 3). Hermeneutika sebagai ilmu tentang semua pemahaman bahasa (science of all linguistic understanding, 4). Hermeneutika sebagai landasan metodologis dari ilmu-ilmu kemanusiaan (methodological foundation of Geisteswissenschaften), 5). Hermeneutika sebagai pemahaman eksistensial, dan 6). Hermeneutika sebagai sistem penafisran.

Hermeneutika sebagai sistem penafsiran dapat diterapkan, baik secara kolektif maupun secara personal, yang gunanya untuk memahami makna yang terkandung dalam mitos-mitos ataupun simbol-simbol. Hermeneutika tidak bisa 
dipisahkan dengan metode sejarah dalam tahap interpretasi. Apabila merujuk ke dalam definisi hermeneutika sebagai metodologi filologi umum dan hermeneutika sebagai sistem penafsiran. Interpretasi adalah tahap memaknai atau memberikan penafsiran terhadap faktafakta yang diperoleh dengan cara menghubungkan satu sama lainnya.

Pada tahapan ini penulisan mengenai sejarah mencoba menafsirkan fakta-fakta yang diperoleh selama penelitian sejarah. Menurut Herlina, Interpretasi atau penafsiran sering disebut sebagai masalah subjektivitas. Sebagian itu benar dan sebagian dari itu salah. Sebagian benar jika yang melakukan interpretasi bukan seorang sejarawan, karena data pada dasarnya tidak bisa memberikan apa-apa tidak bisa bicara. Sejarawan yang jujur, akan mencantumkan data dan keterangan dari mana data itu diperoleh (Herlina, 2008: 36).

Subjektivitas dalam penafsiran
sangat dihindarkan dalam penulisan. Metode yang berada ditahap interpretasi ini membuat seakan sejarah hanya berbicara dalam sudut pandang penulisnya atau sejarawan yang menuliskannya saja. Oleh karena itu, di dalam tahap interpretasi ini terbagi-bagi ke dalam beberapa interpretasi guna mengurangi sikap subjektivitas. Jenis interpretasi itu adalah, 1). Interpretasi Verbal, 2). Interpretasi teknis, 3). Interpretasi logis, 4). Interpretasi psikologis, dan 5). Interpretasi faktual (Herlina, 2008:
39). Hermeneutika sendiri berasal dari kata Yunani hermeneutikos yang berarti penjelasan (explaining/clarifying). Semula merupakan bagian dari filologi untuk mengkritisi otentisitas teks. Bagi historiografi merupakan alat kritik terhadap sumber-sumber sejarah (Bauman, 1978: 7). Pada perkembangannya hermeneutika menjadi aliran filsafat yang bisa di definisikan sebagai teori interpretasi dan penafsiran naskah melalui penelitian. Pada awalnya hermeneutika dipakai untuk menafsirkan Alkitab, terutama dalam studi kritik mengenai Alkitab.

Istilah hermeneutika pun ada yang menjelaskan berasal dari kata Yunani hermencuen, yang berarti menafsirkan, dengan kata dasar hermenia yang berarti tafsiran. Kata hermenecuen didefinisikan menjadi tiga makna, yaitu mengatakan (to stay), menjelaskan (to explain), dan menerjemahkan (to translate), kemudian dalam bahasa Inggris menjadi untuk menafsirkan (to interpret). Perkembangannya menjadi suatu tradisi berpikir atau refleksi filosofis yang mencoba menjelaskan konsep Verstehen, pemahaman.

Hermeneutika mencoba memahami makna sebenarnya (true meaning) dari sebuah dokumen, sajak, teks, teks hukum, tindakan manusia, bahasa, budaya asing, atau dapat juga diri sendiri (Barnes, 1962). Menurut Carl Braathen hermeneutika adalah ilmu yang merefleksikan bagaimana satu kata atau peristiwa di masa dan kondisi 
yang lalu bisa dipahami dan menjadi bermakna untuk masa sekarang juga mengandung aturan metodologis untuk diaplikasikan dalam penafsiran dan asumsi metodologis dari aktivitas pemahaman. Semula hermeneutika berkembang dikalangan gereja dan dikenal dengan gerakan eksegegis (penafsiran teks-teks agama) dan kemudian berkembang menjadi filsafat penafsiran.

Untuk dapat memahami dan membuat penafsiran, seharusnya kita terlebih dahulu memahami dan mengerti. Mengerti dan interpretasi menimbulkan lingkaran hermeneutik. Hukum Betti tentang interpretasi sensus non est inferendus sed efferendus, makna bukan diambil dari kesimpulan tetapi harus diturunkan. Penafsir tidak boleh bersifat pasif, tetapi merekonstruksi makna. Alatnya adalah pemahaman intelektual yang luas dari penafsir, pengalaman hidupnya saat ini, latar belakang sejarah yang dimilikinya.

Hermeneutika pada dasarnya mempunyai tiga makna yang mendasar., yaitu Pertama, mengungkapkan sesuatu yang tadinya masih dalam pikiran melalui kata-kata sebagai medium penyampaian, Kedua, menjelaskan secara rasional sesuatu sebelum masih samar-samar sehingga maknanya dapat dimengerti, dan Ketiga, menerjemahkan suatu bahasa asing kedalam bahasa lain. Dengan demikian hermeneutika merupakan proses mengubah sesuatu atau situasi ketidaktahuan menjadi mengerti. Definisi lain, hermenutika adalah metode atau cara untuk menafsirkan simbol berupa teks untuk dicari arti dan maknanya, metode ini sangat mensyaratkan adanya kemampuan untuk menafsirkan masa lampau yang tidak dialami, kemudian dibawa ke masa kini. Maka dari itu, hermeneutika sangat erat kaitannya dengan interpretasi. Hermeneutika menurut Sjamsuddin termasuk ke dalam kubu historikalis.

Hermeneutika bertolak dari tradisitradisi relativisme (humaniora) dengan tokohnya seperti Dilthey (termasuk juga Croce dan Collingwood), intensionalisme (berbuat dengan maksud atau mencapai suatu tujuan tertentu) dengan tokohnya Rickert dan Windelband (termasuk Dilthey) dan filsafat idealism dengan tokoh-tokohnya Croce dan Collingwood (Sjamsuddin, 2007: 165). Tradisi hermeneutika menjadi point utama pendekatan interpretatif menolak kemungkinan suatu unifikasi (atas dasar empiris atau realis) antara ilmu alam dengan kajian-kajian mengenai perbuatan, sejarah, dan masyarakat.

Hermeneutika menekankan secara tegas perbedaan antara ilmu alam dengan ilmu humaniora. Asal-usul hermeneutika yang sangat panjang ini sebenarnya dapat dirunut sejak Aristoteles (384-322) SM. Namun baru dianggap penting sejak Giambattista Vico (1668-1744) yang menulis buku The New Science pada tahun 1723. Dalam perkembangan selanjutnya 
sesudah Vico, hermeneutika diperkaya dan dpertahankan dari berbagai sudut pandang seperti, romantisme (Herder), hermeneutika awal (Schleiermacher dan Dilthey), neo-kantianisme (Windelband dan Rickert), fenomenologi (Husserl dan Heidegger), filsafat sejarah spekulatif (Croce dan Collingwood), sosiologi (Weber), psiokologi (Freud) dan filsafat bahasa (Wittgenstein) (Sjamsuddin, 2007:166).

Memang tradisi hermeneutika ini menjadi bahasan pula dalam setiap hampir semua cabang kajian manusia yang lain, seperti sastra, psikologi, antropologi, linguistik, dan dengan sendirinya sejarah (Llyod, 1988: 86-87). Jadi pengertian hermeneutika sangat erat hubungannya dengan penafsiran teks-teks dimasa lalu mengenai penjelasan perbuatan pelaku sejarah. Sejarawan disini bertugas memahami objek kajiannya dengan cara menafsirkan makna-makna (meaning) dari semua peristiwa, proses serta perbuatan (action) keseluruhan masyrakat manusia.

Sejarawan menjelaskan masa lalu dengan mencoba menghayati atau menempatkan dirinya dalam diri pelaku sejarah (empati), mencoba memahami dan menjelaskan bagaimana pelaku (para pelaku) sejarah berpifikir, merasakan, berbuat (Sjamsuddin, 2007: 167).

\section{Metode Penelitian}

Metode penelitian yang digunakan dalam penulisan dan penelitian ini adalah metode historis. Metode historis adalah suatu usaha untuk mempelajari dan mengenali fakta-fakta serta menyusun simpulan mengenai peristiwa masa lalu. Tujuannya adalah untuk membuat rekontruksi masa lalu secara sistematis dan objektif (Gottschalk, 2008; Garraghan, 1957: 34). Tahapan penelitian dalam metode sejarah sendiri terbagi menjadi empat.

Tahap pertama adalah heuristik. Heuristik adalah tahapan awal yang dilakukan setelah menentukan topik atau permasalahan penelitian. Heuristik sendiri adalah proses mencari, menemukan dan menghimpun sumber-sumber sejarah yang terkait dengan pokok permasalahan. Tahap pencarian sumber dilakukan terhadap sumber tertulis (studi literatur), sumber benda dan lisan. Sumber tertulis berupa arsip, naskah, sumber resmi tercetak, dokumen, buku dan lain-lain. Arsip ditelusuri di Arsip Nasional Republik Indonesia (ANRI).

Pencarian sumber primer naskah wawacan carios munada dan sumbersumber pendukung lainnya yang sezaman, berbentuk sumber resmi tercetak, surat kabar dan buku. Sumber primer dilakukan di beberapa perpustakaan, diantaranya Perpustakaan Nasional Republik Indonesia (PNRI), Badan Perpustakaan dan Arsip Daerah Provinsi Jawa Barat (BAPUSIPDA), Perpustakaan Fakultas Ilmu Pendidikan dan Ilmu Keguruan (FKIP) Universitas Galuh dan Perpustakaan Program Studi Pendidikan 
Sejarah di FKIP Universitas Galuh Ciamis. Di Perpustakaan Nasional Republik Indonesia penelusuran sumber tertulis dikhususkan kepada pencarian sumber sezaman, seperti surat kabar. Di perpustakaan BAPUSIPDA, FKIP Universitas Galuh dan Prodi Pendidikan Sejarah Universtias Galuh Ciamis dikhususkan kepada pencarian sumber sekunder (buku-buku) pendukung penelitian sumber sejarah perekonomian pada masa kolonial.

Tahap kedua, adalah kritik sumber. Kritik sumber dalam metode sejarah terbagi menjadi dua, yaitu kritik ekstern dan kritik intern. Kritik ekstern untuk menentukan otentisitas sumber dengan cara memberikan penilaian terhadap kondisi fisik sumber tersebut, seperti jenis kertas yang digunakan, tinta, tulisan, huruf, watermark, stempel dan sebagainya. Kritik intern dilakukan dengan melakukan penilaian terhadap kondisi fisik sumber tersebut. Selain itu, akan dilakukan proses membandingkan data yang sudah ada di dalam sumber tersebut dengan data yang ada di dalam sumber lainnya.

Tahap ketiga dalam metode penelitian historis yang digunakan penulis adalah interpretasi dan hermeneutika. Interpretasi adalah proses menafsirkan berbagai fakta menjadi sebuah rangkaian yang logis. Pada tataran operasionalnya, interpretasi dilakukan secara analitis yakni mengurai fakta dan dilakukan secara sintesis yaitu menghimpun fakta.
Pemahaman secara verbal tidak memadai untuk menginterpretasikan informasi yang terkandung di dalam sumber sejarah. Fakta yang diperoleh diinterpretasikan baik secara verbal, teknis, logis, faktual dan psikologis. Dengan demikian, interpretasi yang dihasilkan dapat dipahami secara menyeluruh dan mendalam.

Menurut Schleimacher, hermeneutika adalah bahasan dari sebuah alat baca teks susastra, keagamaan, dan teks klasik lain menjadi sebuah metode utuh (epistemologi) dalam filsafat. Hermeneutika menawarkan beberapa rumusan dalam interpretasi, yaitu rekonstruksi historis, obyektif dan subyektif terhadap sebuah pernyataan. Rekonstruksi obyektif-historis berusaha membahas sebuah pernyataan dalam hubungan bahasa secara keseluruhan. Sementara rekonstruksi subyektif-historis bermaksud membahas awal mula pernyataan masuk dalam pola fikir seseorang.

Tahap selanjutnya adalah tahapan terakhir dalam penulisan sejarah menggunakan historiografi. Historiografi adalah tahapan penulisan sejarah. Fakta yang telah diinterpretasikan kemudian dituliskan dalam penulisan yang sistematis dan kronologis. Historiografi yang akan dihasilkan dibagi menjadi beberapa pembahasan, yang secara keseluruhan merupakan satu kesatuan yang utuh. Dengan menggunakan metode sejarah, penulis mendapat panduan bagaimana 
teknis penelitian jurnal ilmiah ini dapat dikerjakan secara efektif dan akurat. Efektif dalam pengertian tahapan demi tahapan dikerjakan dengan terperinci. Akurat dalam pengertian hanya sumber yang telah menjadi fakta sejarah yang dapat dijadikan bahan penulisan jurnal ilmiah ini. Selain itu, unsur diakronis yang menunjukan sejarah, sebagai ilmu tentang berfikir dalam waktu sangat diperhatikan.

\section{Hasil dan Pembahasan}

\section{A. Wawacan Carios Munada dan Nilai-} nilai Kearifan Lokal

Di dalam naskah ini terdapat ringkasan isi karangan yang bentuk tulisannya berbeda dengan teks inti naskah. Bentuk tulisannya lebih kecil ukurannya dan lebih tipis bekas penanya daripada teks inti naskah. Ringkasan isi itu didasarkan atas nomor halaman naskah. Penulisan naskah ini menggunakan huruf latin. Sistem ejaan yang digunakannya ialah ejaan yang berlaku pada awal abad ke-20. Menurut ejaan ini, antara lain u ditulis oe, $\mathrm{j}$ ditulis dj, c ditulis tj, dan y ditulis j. Tea ditulis teja, biasa ditulis bijasa, dua ditulis doewa, balai ditulis balahi, ieu ditulis ijeu, rai ditulis raji.

Disamping itu, dalam teks naskah ini tertera jumlah kata yang ditulis dengan memperlihatkan pengaruh bahasa dan ejaan bahasa Belanda, seperti resident untuk residen, december untuk desember, koffij untuk kopi, doctor untuk doktor, civir untuk sipir, district untuk distrik, process-verbaal untuk proses verbal, landraad untuk landrad, percent untuk persen, accoer untuk akur, gouvernement untuk gubermen. Dilihat dari sudut ejaan terdapat pula beberapa kesalahan cara menulis, misalnya ngoenjoekeun seharusnya ngunjukkeun, ladang namah, seharusnya ladangna mah, romana seharusnya romanna, sa kalang koeng seharusnya sakalangkung, noerikip seharusnya nu rikip. Ngajoeg2 untuk ngajugjug, ngawang2 untuk ngawangngawang, tak2na untuk taktakna.

\section{B. Nilai-nilai Kearifan Lokal}

Teks dalam naskah ini menggunakan bahasa Sunda. Tampak sekali bahwa bahasa yang digunakannya itu mengandung unsur tingkatan bahasa (undak usuk basa). Tatkala asisten Residen Nagel memarahi Munada, ia menggunakan bahasa kasar; begitu pula ketika bupati Bandung Wiranatakusumah memeriksa nenek-nenek yang menjadi juru kunci suatu tempat di Majalaya, beliau menggunakan bahasa kasar. Percakapan sebaliknya, dari Munada kepada asisten Residen dan dari juru kunci (rakyat biasa) kepada Bupati menggunakan bahasa halus.

Dari sini nilai-nilai kearifan lokal dapat diperlihatkan. Etnis Sunda seluruh wilayah di Jawa Barat klasifikasi status sosial pada saat itu hanya ada status sosial tersebut. Kaum menak sebagai elite politik yang duduk dalam birokrasi tradisional menggunakan kedudukan politik sebagai salah satu cara untuk mempertahankan status mereka. Namun pada perkembangannya golongan menak ini 
kemudian menjadi bermasalah karena banyak rekayasa silsilah dengan menghubungkan pertalian darah atau kekerabatan dengan kaum menak. Pada akhirnya muncul di masyarakat atau keluarga menak adalah banyaknya orang yang mengaku keturunan dari keluarga Bupati. Sedangkan golongan kuring atau rakyat biasa adalah masyarakat yang tinggal di kampung-kampung yang mayoritas bekerja sebagai petani.

Pembicaraan menggunakan Bahasa kasar antara asisten Residen ke pegawainya dan bahasa yang digunakan Bupati Bandung Wirnatakusumah kepada rakyatnya adalah bahasa biasa yang digunakan para pemangku kebijakan kepada rakyat jelata. Namun untuk pegawai pangreh praja kepada asisten Residen atau rakyat biasa kepada Bupati harus menggunakan bahasa yang sangat halus. Karangan dalam naskah ini menggunakan bentuk puisi.

Secara tegas, bentuk tembang yaitu bentuk puisi tradisional yang telah mempunyai aturan-aturan tertentu yang baku baik mengenai jumlah baris per bait, jumlah suku kata per baris, maupun bunyi vokal pada setiap ujung baris. Cerita yang disusun dalam bentuk tembang, dalam khazanah sastra Sunda disebut wawacan. Demikian pula, karangan dalam naskah ini adalah tergolong wawacan. Hal itu diakui sendiri oleh pengarangnya sebagaimana dinyatakan dalam judul karangannya. 219 Wawatjan Tjarios Moenada anoe prantos kadjadian hoeroe-hara di negri Bandoeng di kaping 30 boelan December tahoen 1842 (219 Wawacan Cerita Munada, suatu peristiwa huru-hara yang terjadi di kota Bandung tanggal 30 Desember 1642). Angka 219 kiranya menunjukan nomor naskah yang dibuat oleh mungkin redaktur atau tata usaha Balai Pustaka di Jakarta.

Rupanya naskah ini (bersama sejumlah naskah lain) pada mulanya dikirim oleh pengarangnya ke Bale Pustaka di Jakarta (waktu itu: Batavia) untuk mohon diterbitkan. Namun tampaknya karangan ini tergolong yang ditolak oleh redaksi Bale Pustaka untuk diterbitkan sehingga kemudian dikirimkan ke Leiden. Alasan penolakannya adalah karena isi karangan mengungkapkan kekurangan patutan perilaku dan kelemahan pejabat pemerintah kolonial yang adalah orang Eropa.

Naskah ini diperuntukkan bagi Balai Pustaka (badan penerbitan yang diselenggarakan oleh pemerintah), terlihat juga dari pernyataan pengarang yang sesuai dengan kebijakan pemerintah (kolonial) waktu itu dalam bidang penerbitan buku, yaitu menciptakan keadaan masyarakat dan negara yang tertib dan aman. Pemerintahan kolonial yang dipegang oleh Maharatu Wihelmina di Nederland dan raja Hindia Kanjeng Tuan Besar Gubernur Jenderal, juga menyanjungnya dengan menyatakan bahwa Maharatu Nederlan itu bijaksana dan raja Hindia itu adil, berbudi, dan sayang terhadap rakyat. Lokasi Banonciawi, 
berdasarkan keterangan yang tertera pada halaman 1 naskah maupun menurut keterangan pada kolofon naskah, karangan di dalam naskah ini (Wawacan Carios Munada) disusun oleh Mas Kartadinata. Ia adalah seorang yang bekerja di lingkungan Perusahaan Negara Kereta Api yang biasa disingkat SSI. Pernah menduduki jabatan kepala stasiun (Chops Statsiun) kereta api Raja polah, sebuah stasiun kereta api yang terletak dijalur jalan kereta BandungTasikmalaya. Raja polah adalah sebuah kota kecamatan di daerah Kabupaten Tasikmalaya (dulu Soekapoera).

Mas Kartadinata mengarang pula sebuah wawacan lain berjudul Rasiah Priangan (Rahasia Priangan). Karangan ini selesai disusun pada tanggal 24 Maret 1916, dan diterbitkan oleh Balai Poestaka pada tahun 1921. Rasiah Priangan berisi tentang kerusuhan yang terjadi di daerah selatan Kabupaten Bandung yang dilancarkan oleh sekelompok masyarakat pimpinan Raksa Praja dan di belakangnya terlibat patih Bandung Rd Rangga Adikusumah yang berambisi ingin menjadi Bupati Bandung.

Secara prinsip karangan ini menuturkan kisah yang bertalian dengan menak (bangsawan) Bandung, seperti akan terlihat nanti pada isi karangan wawancara carios munada. Di lihat dari sudut pandang tersebut yang mana Mas Kartadinata sangat tertarik dan mengetahui benar seluk beluk kehidupan para menak Bandung, tampaknya berasal dari lingkungan yang dekat hubungannya dengan menak Bandung. Gelar mas di depan namanya bukan menunjuk kepada identitas menak, melainkan merupakan ciri keturunan orang Jawa yang telah bermukim lama di Priangan, dengan kedudukan sosialnya lebih tinggi dari masyarakat biasa. Terlebih karena menjadi pegawai perusahaan negara dan pernah menduduki pimpinan betapapun rendahnya.

\section{Penutup}

\section{Kesimpulan}

Keseluruhan isi naskah wawacan carios munada ini disusun dengan menggunakan 12 jenis pupuh. Ke 12 jenis dimaksud adalah 1. Asmarandana, 2. Sinom, 3. Dangdanggula, 4. Kinanti, 5 Mijil, 6. Pangkur, 7. Pucung, 8. Magatru, 9. Durma, 10 Gambuh, 11. Wiragrong, dan 12. Balakbak. Penggunaan pupuh tersebut dilakukan secara berselang seling tanpa aturan tertentu. Dalam pada itu, karakter pupuh berkaitan dengan isi cerita kurang mendapat penakanan sehingga tak lelas pemakaiannya (Ekadjati, 1992: 134).

Pupuh Asmarandana misalnya tidak selamanya dipakai untuk mengungkapkan suasana percintaan dirundung Asmara, melainkan juga suasana sedih dan hanya untuk menyebutkan nama-nama tokoh beserta jabatannya. Pupuh balakbak tidak selalu untuk menggambarkan suasana lucu atau lawakan melainkan untuk menggambarkan suasana duka. Pupuh 
Asmarandana digunakan sebanyak 3 kali dan berjumlah 159 bait, kesatu sampai 25 . 325-363, 551-579, 801-832, dan 917-965. Sinom dipakai sebanyak 7 kali dan berjumlah 160 bait yaitu bait-bait ke 26-50, 285-309, 413-434, 580-609, 708-750, 902916 dan 936-1006. Dangdanggula digunakan sebanyak 4 kali dan berjumlah 111 bait, yaitu bait-bait yang ke-; 51-74, 224-254, 489-517, dan 681-707. Kinanti dipakai sebanyak 3 kali dan berjumlah 5 bait, yaitu bait-bait ke: 75-103, 300-412, dan 833-863.

Mijil dipakai sebanyak 4 kali dan berjumlah 83 bait, yaitu bait-bait ke: 104123, 655-680, 886-901, dan 1007. Pangkur digunakan sebanyak 3 kali berjumlah 93 bait, yaitu bait-bait ke: 124-157, 310-339, dan 460-488. Pucung digunakan sebanyak 3 kali dan berjumlah 104 bait, yaitu bait-bait ke: 158-206, 516-550, dan 864-885. Magatru digunakan sebanyak 1 kali dan berjumlah 17 bait, yaitu bait ke: 207-223. Durma digunakan sebanyak 3 kali dan berjumlah 105 bait, yaitu bait-bait ke: 255284, 435-459, dan 731-800.

Gambuh digunakan sebanyak 1 kali, dan berjumlah 45 bait, yaitu pada bait ke: 610-654. Wiragrong sebanyak 1 kali, dan berjumlah 24 bait, yaitu pada bait ke: 364387 serta Balakbak sebanyak 1 kali dan berjumlah 20 bait, yaitu pada bait ke: 966985. Menarik perhatian bahwa di dalam naskah wawacan carios munada terdapat sejumlah gambar yang terletak pada halaman tertentu disebelah teks sehingga diberi nomer kode tambah a-. Gambar dimaksud yang hitam putih beserta lokasi penempatannya mencerminkan gambaran isi cerita. Dengan demikian, daftar urutan gambar sesuai dengan urutan jalan cerita. setiap gambar dilengkapi dengan keterangan singkat. Seluruhnya ada 28 buah gambar. Ke-28 gambar itu terletak pada halaman: 4a, 10a, 13a, 20a, 23a, 26a, 30a, 34a, 37a, 39a, 42a, 51a, 54a, 57a, 66a, 75a, 79a, 88a, 92a, 101a, 105a, 112a, 117a, 126a, 133a, 140a, 148a, dan 154a.

Beberapa buah gambar beserta keterangannya, antara lain 1). Munada atau Liem Siang sewaktu muda, rambutnya tampak dicukur, suatu cara penataan rambut model lama bagi orang China, 2). Munada sedang ditagih hutang oleh asisten presiden Nagali, 3). Munada sedang dijamu makan oleh Wedana Blubur-Limbangan Arsaen, sementara wedana sendiri membaca surat Asisten Presiden Nagali,

4). Bupati Bandung yang didampingi permaisurinya sedang memerika selirnya yang mengandung oleh asisten presiden Nagali, 5). Adam Eros putra asisten Presiden Nagali dari selir Bupati sedang bermain burung di taman belakang pendopo Kabupaten, 6). Bapak Ujen melapor kepada patih tentang pembunuhan Nyi Asmah oleh suaminya, 7). Mas Suradiraja, suami Nyi Asmah dimasukan kedalam penjara, 8). R Surya Kusumadinata menikah dengan R.A Rajapamerat puteri Bupati Bandung, 9). 
Munada sedang menggiring kerbau dan kuda, 10). Bupati Bandung dengan Wedana Majalaya yang dikenai sangsi, 11). Jaksa Surialaya sedang membujuk R. Salimantri, istri muda Jaksa Bandung, 12). Bupati Bandung di dampingi Jaksa Surialaya melapor kepada Resident Colemberg di Lodji Bandung, 13). R. Ditakusumah mendorong mayat Munada, dan 14). Bupati Bandung Dalem Karang Anyar berunding dengan 3 orang putranya.

\section{Daftar Pustaka}

Barnes, Harry Helmer. (1962). A History of Historical Writing. New York: Dover Publications, Inc.

Bauman, Zygmunt. (1978). Hermeneutics and Social Science. Approach to Understanding

Carr, E.H. (1961). What Is History. New York: Penguin Book.

Ekadjati. Edi.S. (1992). Wawacan Carios Munada. Bandung: Departemen Pendidikan dan Kebudayaan.

Gottschalk, L. (1985). Mengerti Sejarah. Jakarta: UI Press.

Herlina, Nina. (2008). Metode Sejarah. Bandung: Satya Historika.

Llyod, Christhoper. (1988). Explanation in Social History. Cowley Road, Nebraska: Cliff's Notes, inc.

Sjamsuddin, Helius. (2007). Metodologi Sejarah. Yogyakarta: Penerbit Ombak. 